\title{
An Alternate Technique to Simplify the Process of Painting Ocular Prosthesis with the Use of Acrylic Colors
}

\author{
Bhochhibhoya $\mathrm{A}^{1^{*}}$, Mathema $\mathrm{S}^{2}$ \\ ${ }^{1}$ Lecturer, Department of Prosthodontics, Nepal Medical College, Nepal \\ ${ }^{2}$ Professor and Head of Department, Department of Prosthodontics, People's Dental College and Hospital, Nepal
}

$\mathrm{T}$ The mutilation of a part of the face, particularly the eye, has a crippling effect on the person's personality which causes significant physical and emotional difficulties due to the functional disability and public reactions to the disfigurement. 1,2 Prosthetic rehabilitation of ocular defect with a cosmetically acceptable prosthesis that reproduces the color,form and orientation of iris is required to endorse psychological comfort to the patient and to make them socially acceptable. ${ }^{3}$ Various techniques of iris painting include paper iris disc technique, black iris disc technique and monopoly with dry earth pigment. ${ }^{4}$ Opportunities are available during the steps in painting to blend and apply color tones which give a closer matching to the normal eye than can be achieved from stock eye selections. ${ }^{5}$ This customized ocular prosthesis is esthetically natural to the patient and to the observer and is durable. However, further research is necessary to evaluate the longterm color stability and aging of these ocular prosthesis.

This report presents an alternate technique to simplify the process of painting of the ocular prosthesis with the use of acrylic colors. The technique described here is easy, economical, less time consuming and yields reliable esthetic results.

\section{*Corresponding Author}

Dr. Amar Bhochhibhoya, Lecturer, Department of Prosthodontics, Nepal Medical College,Kathmandu, Nepal.

Email: amarbhochhibhoya@gmail.com

\section{Procedure}

1. Fabricate the scleral blank with heat polymerizing acrylic resin (Trevlon, Dentsply) the shade of which is initially matched with the scleral portion of the natural eye. Trim $1 \mathrm{~mm}$ along the outer surface of the scleral blank. (Fig. 1)

2. Acrylic resin paints (Artists' acrylic color, Camlin) are supplied in red, yellow, blue, white, and brown. These basic colors can be blended to match all eye colors. Dispense the appropriate acrylic colors on a glass plate and mix with monopoly to form colored syrup. (Fig. 2) Prepare monopoly by combining 10 parts of heat cure acrylic resin monomer to 1 part of clear acrylic resin polymer by weight.

3. Paint iris portion of scleral blank in a layering fashion to mimic the colored striations in the patient's iris. The sequence of the technique of painting the artificial eye is as follows: the stroma (the predominant iris color), the background (the colors shown at limbus), the collarette (the area surrounding the pupil), and the markings (the striations on the anterior surface). ${ }^{6}$

4. Apply the colors with a small paint brush in a circular pattern radiating outward from the center. Use the good thick layer of the darkest base shades first, progressing to the lighter individual colors.

5. Mix and apply the collarette color, streaking it lightly over the base colors. Finally, mix and apply the lightest color in very fine, 
radiating strokes. Striations are developed in the pigments by using light strokes in overlaying the different colors. (Fig. 3)

6. Use a hot air drier to accelerate the setting of each layer. Paint a dark black spot in the center of iris to represent the pupil and check the painted iris portion of scleral blank for color accuracy against the existing eye under natural light.

7. Then mix and apply the limbus color to the periphery and reproduce their gradual fuzzy blending into the sclera and iris

8. Attach rayon filaments of various desired lengths to the sclera using monopoly which is used to simulate patient's vasculature. The vessels are terminated at the limbus, medial and lateral canthi. (Fig. 4)

9. Mix heat cure clear acrylic resin (Trevlon, Densply) in the ratio $3: 1$ and allow the mixture to stand to dough stage. Pack the mold containing scleral blank with the acrylic dough. This laminate of clear acrylic gives a life like appearance and depth for the characterization. Close the flask and heat cure the resin. Avoid paint from smudging and allow polymerization by gradual rise of temperature and final boiling. (Fig. 5)

10. Finish and polish the ocular prosthesis to a high shine, disinfect and store in water for 24 hours before insertion. (Fig. 6)

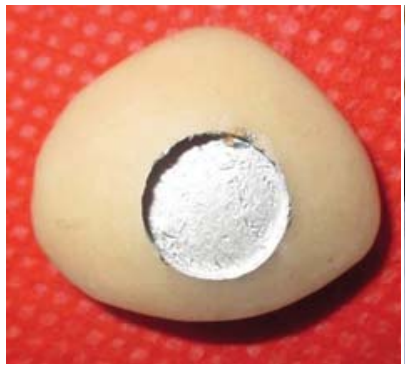

Figure 1: Heat polymed acrylic resin scleral blank

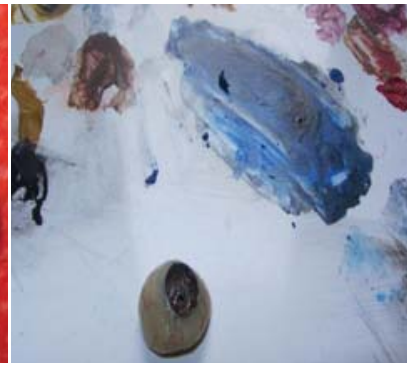

Figure 2: Acrylic colors mixed with monopoly to form colored syrup

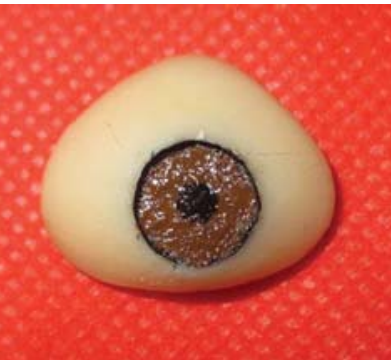

Figure 3: Painted iris portion of scleral blank

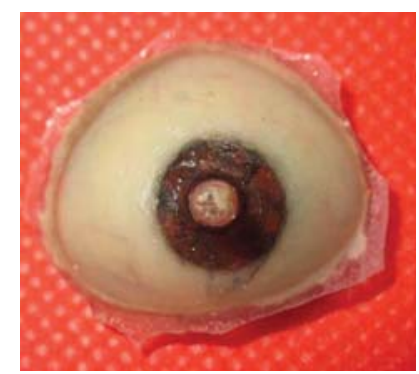

Figure 5: Laminate of clear acrylic over painted sclera blank

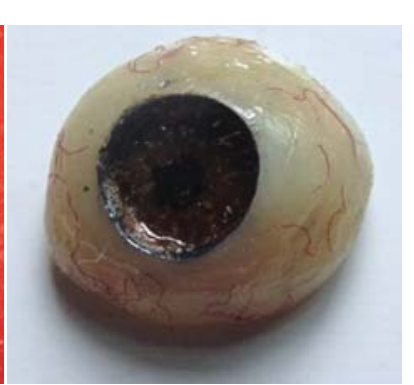

Figure 4: Rayon filaments attached to the sclera blank to stimulate vasculature

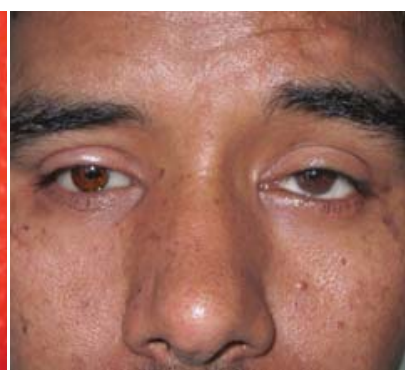

Figure 6: Insertion of finished and polished ocular prosthesis (Right Eye)

\section{References}

1. Perman KI, Baylis HI. Evisceration, enucleation, and exenteration.OtolaryngolClin North Am 1988; 21: 171-82.

2. Lubkin V, Sloan S. Enucleation and psychic trauma. AdvOphthPlastReconstrSurg 1990; 8: 259-62.

3. Jain S, Makkar S, Gupta S, Bhargava A. Prosthetic rehabilitation of ocular defect using digital photography: A case report. J Indian ProsthodontSoc2010;10:190-93.

4. Jain DC, Hegde V, Aparna IN, Dhanasekar B. Ocular prosthesis: An esthetic vision. J Nepal Dent Assoc 2010;11:101-06.

5. Cain JR. Custom ocular prosthetics. J Prosthet Dent 1982;48:690.

6. Bartlett SO, Moore DJ. Ocular prosthesis: A physiologic system. J ProsthetDent 1973;29:450. 